\title{
Baz Ticari ve Yerel Yulaf Genotiplerinin Çimlenme ve Fide Gelişimi Üzerine Tuz Stresinin Etkileri
}

\author{
Hüseyin GÜNGÖR ${ }^{1} \quad$ Yakup ÇIKILI $^{2} \quad$ Ziya DUMLUPINAR ${ }^{3}$ \\ ${ }^{1}$ Düzce Üniversitesi Ziraat ve Doğa Bilimleri Fakültesi Tarla Bitkileri Bölümü, Düzce \\ ${ }^{2}$ Düzce Üniversitesi Çilimli Meslek Yüksekokulu Bitkisel ve Hayvansal Üretim Bölümü, Düzce \\ ${ }^{3}$ KSÜ Ziraat Fakültesi Tarımsal Biyoteknoloji Bölümü, Kahramanmaraş \\ $\bowtie$ : hgungor78@hotmail.com
}

\begin{abstract}
ÖZET: Bu çalışma, bazı ticari ve yerel yulaf genotiplerinin çimlenme ve erken fide gelişim dönemlerinde oluşturulan tuz stresine tepkilerini belirlemek amacıyla, Düzce Üniversitesi, Çilimli Meslek Yüksekokulu laboratuvarında 2016 yılında yürütülmüştür. Araştırmada, 10'u tescilli, 6 yerel olmak üzere 16 yulaf genotipine, 0 (kontrol), 50 ve $100 \mathrm{mM}$ dozlarında tuz $(\mathrm{NaCl})$ stresi uygulanmıştır. Araştırmada genotiplerin, 24. Saatteki su alım oranı (\%), çimlenme yüzdeleri (\%), kök uzunlukları $(\mathrm{cm})$, sürgün uzunlukları $(\mathrm{cm})$, kök yaş ağırlıkları $(\mathrm{mg} /$ bitki), sürgün yaş ağırlıkları (mg/bitki), kök kuru ağılıkları (mg/bitki), sürgün kuru ağılıkları (mg/bitki), tuz dayanıklılık indeksi (\%) ve tohum güç indeksi değerleri incelenmiştir. İncelenen tüm özellikler yönüyle genotipler, tuz konsantrasyonu ve genotip x tuz konsantrasyonu interaksiyonları istatistiksel olarak önemli bulunmuştur. Genotiplerin incelenen özellikler bakımından tuzluluğa tepkileri farklı olmuştur. Artan tuz konsantrasyonları yulaf genotiplerinin hem çimlenmesini hem de fide gelişimini olumsuz yönde etkilemiştir. Tuz dayanıklılık indeksi değerleri bakımından TL558, Arslanbey ve Faikbey genotipleri tuza dayanıklı olarak öne çıkmışlardır.
\end{abstract}

Anahtar kelimeler: Yulaf, çimlenme, tuz stresi, fide gelişimi, $\mathrm{NaCl}$

\section{The Effects of Salt Stress on Germination and Seedling Development of Some Commercial and Landraces of Oat Genotypes}

\begin{abstract}
This study was conducted to determine salt stress response of some commercial and landraces of oat genotypes at Düzce University, Çilimli Vocational School Laboratories in 2016 year. In the research totally 16 genotypes as 10 commercials and 6 landraces were treated by 0 (control), 50 and $100 \mathrm{mM}$ salt $(\mathrm{NaCl})$ doses. In the study water uptake ratio $(\%)$, germination ratio $(\%)$, root length $(\mathrm{cm})$, shoot length $(\mathrm{cm})$, root fresh weight $(\mathrm{mg} / \mathrm{plant})$, shoot fresh weight (mg/plant), root dry weight (mg/plant), shoot dry weight $(\mathrm{mg} / \mathrm{plant})$, salt tolerance index (\%) and seed vigor index traits of oat genotypes were investigated. The response of genotypes varied for salt stress. The increasing rates of salt concentrations negatively affected germination and seedling development of oat genotypes. According to the salt tolerance index, TL558, Arslanbey and Faikbey genotypes were found tolerant.

Keywords: Oat, germination, salt stress, seedling development, $\mathrm{NaCl}$
\end{abstract}

\section{GİRIŞ}

Tuzluluk, özellikle kurak ve yarı-kurak alanlarda üretimi kıstlayan en önemli problemlerden birisidir. Dünya'da 831 milyon hektar alanda tuzluluk problem söz konusuyken, Türkiye'de 1.5 milyon hektar alanda hem tuzluluk hem de alkalilik problem oluşturmaktadır (FAO, 2000). Tuzlu topraklar bitkilerin farklı gelişme dönemlerinde bitki gelişimini engelleyecek miktarda çözülebilir tuz içerirler ve bitkilerin verimliliklerinde, farklı dönemlerdeki gelişimlerinde ve bitki bünyesinde meydana gelen bazı biyokimyasal ve fizyolojik olaylarda kisitlayıc1 rol oynarlar (Al-Mutawa, 2003; Mahmood ve ark., 2010; Nawaz ve ark., 2010). Kumar ve ark. (2014), sekiz farklı yulaf genotipinin $3,6,7.2,10,12$ ve $14 \mathrm{dSm}$ ${ }^{1}$ elektriksel iletkenliğe sahip tuz konsantrasyonlarındaki çimlenme yüzdesi, fide yaş ve kuru ağıllıklarını incelemişlerdir. Araştırıcılar, artan tuz konsantrasyonlarına bağlı olarak incelenen özelliklerde önemli azalmaların meydana geldiğini bildirmişlerdir. Mu ve ark. (2015), erken gelişme dönemi yulaf fideleri üzerine beş farklı tuz konsantrasyonunun $(48,72,96,120$ ve $144 \mathrm{mmolL}^{-1}$ ) büyüme ve fizyolojik etkilerini inceledikleri çalışmalarında tuz konsantrasyonlarının artması ile birlikte kardeş sayısı, klorofil, $\mathrm{K}, \mathrm{Ca}, \mathrm{NO}^{-3}$, $\mathrm{H}^{2} \mathrm{PO}^{-4}$, sürgün uzunluğu, sürgün biyomas ve su içeriğinde önemli azalmaların meydana geldiğini bildirmişlerdir.

$\mathrm{Bu}$ araştırma, bazı ticari ve yerel yulaf genotiplerinin fazrklı tuz konsantrasyonlarındaki çimlenme ve erken fide gelişmelerinin belirlenmesi amaciyla yürütülmüştür.

\section{MATERYAL ve YÖNTEM}

Araştırma, Düzce Üniversitesi Çilimli Meslek Yüksekokulu Bitkisel Üretim Bölümü Bitki Fizyolojisi Laboratuvarında 2016 y1lında yürütülmüştür. Denemede 10 ticari (Seydişehir, Checota, Faikbey, Kırklar, Kahraman, Arsanbey, Fetih, Yeniçeri, Sarı ve Sebat) ve 6 yerel hat (TL 5, TL 16, TL 488, TL 558, TL 582 ve TL 431) toplam 16 yulaf genotipi kullanılmıştır. Çalışmada 3 farklı tuz konsantrasyonu $(0,50$ ve $100 \mathrm{mM})$ ele alınmıştır. Araştırma, tesadüf parselleri deneme desenine göre üç tekerrürlü olarak yürütülmüştür. Denemede 
homojen bir ortamın sağlanması açısından çimlendirme öncesi her genotype ait tohumların kavuzları soyulmuştur. Tohumlar çift katlı filtre kağıdı bulunan petri kaplarına yerleştirilmiştir. Çift katlı filtre kağıtları arasına konulan tohumların üzerine $15 \mathrm{ml}$ farklı tuz yoğunlukları içeren solüsyonlar konulmuştur. Her petri kabına 20 tohum konulmuştur. Petri kapları daha sonra $25 \pm 1{ }^{\circ} \mathrm{C}^{\prime}$ de 8 gün boyunca çimlenmeye bırakılmıştır. Araştırmada tohumların ilk 24. Saatteki su alım oranını (SAO) tespit etmek amaciyla verilen eşitlikten yararlanılmıştır. SAO $(\%)=\quad(\mathrm{A} 2-\mathrm{A} 1 / \mathrm{A} 1) * 100$ (Akbarimoghaddam ve ark., 2011). A1:Tohumun ilk ağırlığı, A2: 24.saatteki tohum ağırlığıdır. Çimlenme oranı için, kökçügü en az $1 \mathrm{~mm}$ geçen tohumlar çimlenmiş olarak kabul edilmiştir (Atak ve ark., 2006; Kara ve ark., 2011). Her petri kabından 10 örnek alınmıș ve bu örneklerde kök ve sürgün uzunluğu, kök ve sürgün yaş ağırlıkları ölçülmüştür. Kök ve sürgün kuru ağırlıkları ise yaş ağırlıkların 70 C'de 48 saat kurutulup tartılmalarıyla bulunmuştur. Ayrıca, fidelerin toplam kuru ağırlıkları kullanılarak verilen formülle "tuz tolerans indeksi” (Çarpıcı ve ark., 2009; Kökten ve ark., 2010) hesaplanmıştır. Tuz tolerans indeksi: (TxTKA/T0TKA)x100, Tx: X tuz dozundaki toplam kuru ağırlığı, T0: kontrol uygulamasındaki toplam kuru ağırlığı ifade etmektedir. Ayrıca, genotiplerin tohum güç indeksleri (TGI), kök uzunluğu ve sürgün uzunluğunun çimlenme yüzdesi ile çarpılması ile hesaplanmıştır (Dhanda ve ark., 2004). Araştırmadan elde edilen veriler Tesadüf Parselleri Deneme Deseni'ne göre, JMP 7 istatistik paket program kullanılarak varyans analizine tabi tutulmuş olup, ortalamaların karşılaştırılmasında Duncan çoklu karşılaştırma testi kullanılmıştır (JMP, 2007).

\section{BULGULAR ve TARTIŞMA}

Bazı ticari ve yerel yulaf genotiplerinin farklı tuz konsantrasyonlarındaki 24. Saatteki su alım oranları, çimlenme yüzdeleri, kök uzunlukları, sürgün uzunlukları, kök yaş ağırlıkları, sürgün yaş ağırlıkları, kök kuru ağırlıkları, sürügün kuru ağırlıkları, tuz tolerans indeksleri ve tohum güç indeksleri değerlerine ait varyans analiz sonuçlarına göre incelenen tüm özellikler bakımından genotipler, tuz konsantrayonları ve GenotipxTuz konsantrasyonu interaksiyonu istatistiki anlamda önemli bulunmuştur.

ilk 24 saat sonunda en yüksek su alım oran1 \% 49.01 ile TL 558, en düşük su alım oranı ise $\% 37.48$ ile TL 5 genotipinde tespit edilmiştir. Tuz konsantrasyonlarının 24. Saatteki su alım oranı üzerine etkisi olumsuz yönde olmuş ve tuz konsantrasyonlarındaki artışa bağlı olarak su alım oranı da azalmıştır. En yüksek su alım oranı $\%$ 45.99 ile kontrolden elde edilirken en düşük değer ise \% 36.88 ile en yüksek tuz konsantrasyonundan (100 mM) elde edilmiştir (Çizelge 1). Artan tuz konsantrasyonları ortamın osmatik basıncını arttırmış ve bu da tohumların su alım oranını düşürmüştür. Bu araştırmanın sonuçlarına benzer şekilde Akbarimoghaddam ve ark. (2011), Doğan ve Çarpıcı (2015), Doğan ve Çarpıcı (2016) artan tuz konsantrasyonlarının tohumların su alım oranlarını önemli ölçüde azalttığını tespit etmişlerdir.

Çimlenme yüzdesi bakımından genotipler arasındaki farklılık istatistiki olarak \% 1 olasılık düzeyinde önemli bulunmuştur. En yüksek çimlenme yüzdesi Yeniçeri genotipinden (\% 88.88), en düşük çimlenme yüzdesi ise Kahraman genotipinden (\% 66.67) elde edilmiştir. Artan tuz konsantrasyonlarına bağlı olarak çimlenme yüzdesi giderek azalmıştır. En yüksek çimlenme yüzdesi kontrolde (\% 97.71), en düşük çimlenme yüzdesi ise 100 $\mathrm{mM}$ tuz konsantrasyonundan (\% 44.79) tespit edilmiştir (Çizelge 1). Elde ettiğimiz sonuçlar artan tuz dozlarında çimlenme yüzdelerinin azaldığını bildiren bir çok araştırmacının sonucu ile uyum içerisindedir (Atış, 2011; Uyanık ve ark., 2014; Doğan ve Çarpıcı, 2016).

Yulaf genotipleri arasında kök uzunluğu bakımından önemli farklılıklar ortaya çıkmıştır. En uzun kök uzunluğu Kahraman, en kisa kök uzunluğu ise TL 5 genotipinden tespit edilmiştir. Artan tuz konsantrasyonları sonucunda kök uzunluğu önemli ölçüde kısalmış ve kontrol'e göre $100 \mathrm{mM}$ tuz konsantrasyonunda kök uzunluğunda \% 50 azalma meydana gelmiştir. Kök uzunluğu bakımından genotip x tuz konsantrasyonu interaksiyonu önemli çıkmış ve bunun sonucunda da Kahraman çeşidi $10.56 \mathrm{~cm}$ ile $0 \mathrm{mM}$ tuz dozunda en yüksek kök uzunluğu değerine sahip olurken, TL 16 genotipi ise $0.67 \mathrm{~cm}$ ile $100 \mathrm{mM}$ tuz dozunda en düşük değere sahip olmuştur (Çizelge 1). Benzer sonuçlar Atış (2011), Uyanık ve ark. (2014) tarafindan da tespit edilmiştir.

Yulaf genotipleri arasında sürgün uzunluğu bakımından önemli farklılıklar ortaya çıkmıştır. En uzun sürgün uzunluğu TL $582(9.21 \mathrm{~cm})$, en kısa sürgün uzunluğu ise Sebat genotipinden $(5.3 \mathrm{~cm})$ tespit edilmiştir. Artan tuz dozları sonucunda sürgün uzunluğu önemli ölçüde kısalmış ve kontrol doza göre $100 \mathrm{mM}$ tuz dozunda kök uzunluğunda \% 57 azalma meydana gelmiştir. Sürgün uzunluğu bakımından genotip x tuz konsantrasyonu interaksiyonu önemli çıkmış ve bunun sonucunda da Faikbey çeşidi $18.23 \mathrm{~cm}$ ile $0 \mathrm{mM}$ tuz dozunda en yüksek sürgün uzunluğu değerine sahip olurken, Kahraman çeşidi ise $1.10 \mathrm{~cm}$ ile $100 \mathrm{mM}$ tuz dozunda en düşük değere sahip olmuştur (Çizelge 1). Artan tuz dozuna göre sürgün uzunluğunun azalması tuz stresine bağlı olarak iyon toksitesi ve osmotic basıncın etkisiyle su alımının engellenmesi ile açıklanabilir. Benzer sonuçlar Atış (2011), Uyanık ve ark. (2014) tarafından da tespit edilmiştir.

Genotipler arasında en yüksek kök ve sürgün yaş ağırlığı Sarı genotipinden elde edilmiştir. Artan tuz konsantrasyonları kök ve sürügün yaş ağırlıkları üzerindeki etkileri olumsuz yönde olmuş ve tuz konsantrasyonu arttıkça yaş ağırlıklarda da azalmalar meydana gelmiştir. Tuz konsantrasyonlarındaki artış sürgün gelişimini kök gelişimine oranla daha fazla etkilemiştir. Atak (2014), artan tuz dozlarının sürgün gelişimi üzerine daha fazla olumsuz etkiye sahip olduğunu bildirmiştir. Genotip x Tuz konsantrasyonu interaksiyonu önemli çıkmıştır. Kök yaş ağırlıkları 9.27 mg (Faikbey-100mM)-64.45 mg (Fetih-0 mM), sürgün 
yaş ağılıkları ise $9.57 \mathrm{mg}$ (TL16-100 mM)-119.78 mg (Sarı-0 mM) arasında değişmiştir (Çizelge 2).

Çizelge 1. Su alım oranı, Çimlenme yüzdesi, Kök uzunluğu ve Sürgün uzunluğu özelliklerine ilişkin ortalama değerler.

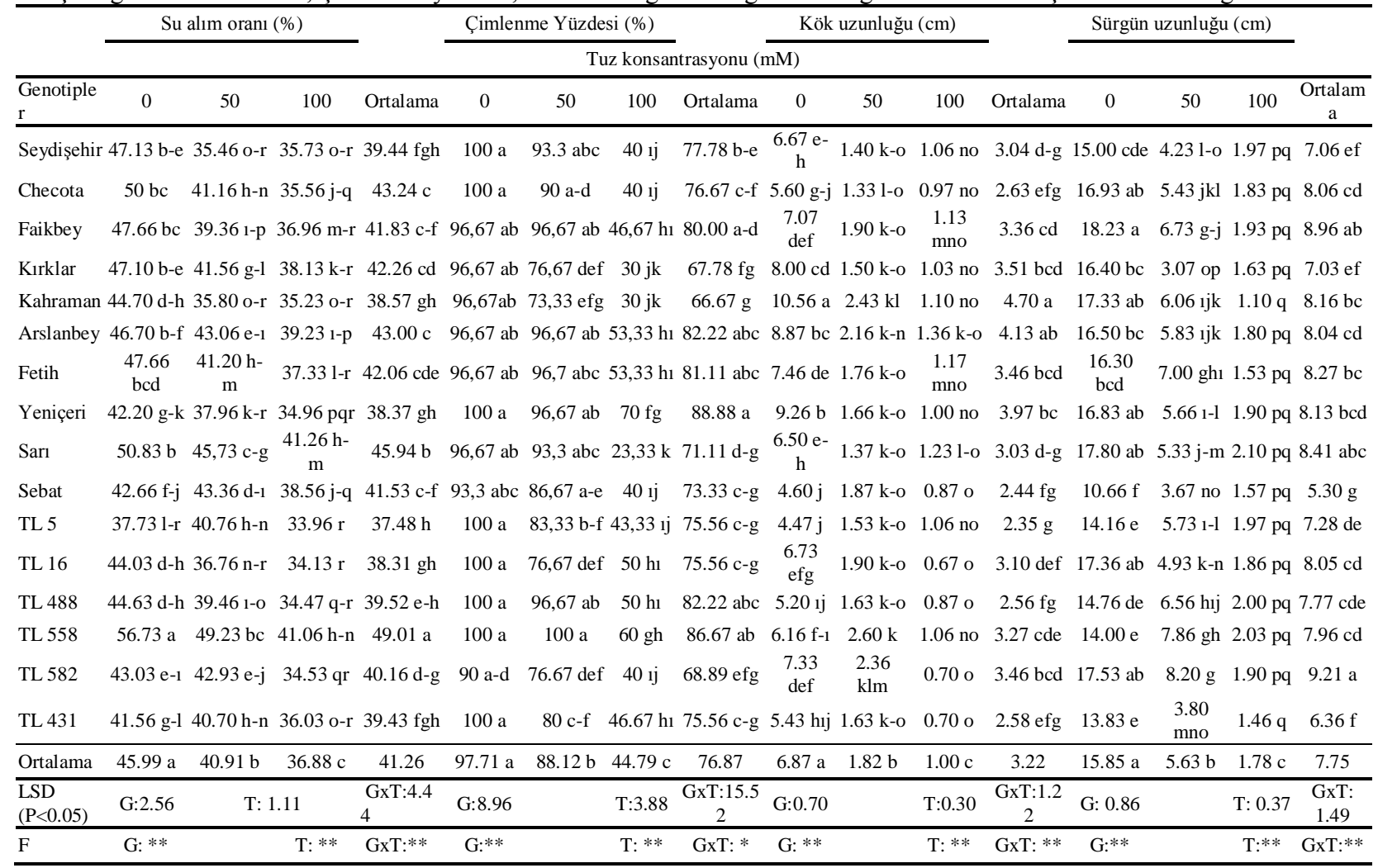

Çizelge 2. Kök yaş ağırlığı, Sürgün yaş ağırlığı, kök kuru ağırlığı ve sürgün kuru ağırlığı özelliklerine ilişkin ortalama değerler.

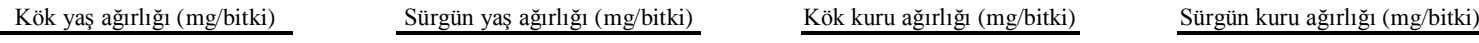
Tuz konsantrasyonu (mM)

\begin{tabular}{|c|c|c|c|c|c|c|c|c|c|c|c|c|c|c|c|c|}
\hline $\mathrm{er}$ & 0 & 50 & 100 & & 0 & 50 & 100 & ama & 0 & 50 & 100 & & 0 & 50 & 100 & \\
\hline & r 44.7 & & & & & & & & & & $\mathrm{O}-\mathrm{s}$ & & & & $q-u$ & \\
\hline & $43.50 \mathrm{c}$ & $20.07 \mathrm{jkl}$ & $11.94 \mathrm{~s}-\mathrm{v}$ & $25.17 \mathrm{~d}-\mathrm{g}$ & $95.20 \mathrm{de}$ & $44.74 \mathrm{~lm}$ & $11.97 \mathrm{pqr}$ & $50.64 \mathrm{~b}-\mathrm{f}$ & $4.03 \mathrm{c}-\mathrm{h}$ & & $2.05 \mathrm{o}-\mathrm{t}$ & & $10.86 \mathrm{a}$ & & $q-u$ & $7 \mathrm{ab}$ \\
\hline & 42.37 & & $9.27 \mathrm{v}$ & & & & & & & & & & & & & \\
\hline & & 21.701 & & $31.97 \mathrm{bc}$ & $109.17 \mathrm{~b}$ & $36.60 \mathrm{mno}$ & $11.00 \mathrm{qr}$ & $52.26 \mathrm{~b}-\mathrm{e}$ & $6.31 \mathrm{a}$ & & $1.55 \mathrm{q}-\mathrm{u}$ & & $11.21 \mathrm{a}$ & & & \\
\hline ahraman & $51.88 \mathrm{bc}$ & $27.58 \mathrm{j}-\mathrm{r}$ & $.11 \mathrm{~s}-\mathrm{v} 3$ & $30.19 \mathrm{bcd}$ & $107.58 \mathrm{bc}$ & $46.63 \mathrm{kl}$ & $10.33 \mathrm{qr}$ & $54.85 \mathrm{~b}$ & $4.97 \mathrm{bc}$ & $3.80 e-j$ & $1.44 \mathrm{stu}$ & $3.41 \mathrm{bc}$ & $11.40 \mathrm{a}$ & $8.20 \mathrm{~d}-\mathrm{j}$ & & \\
\hline ey 4 & 46.13 cde & $25.96 \mathrm{k}$ & $13.87 \mathrm{q}-\mathrm{v}$ & 28.65 cde & $83.46 \mathrm{f}$ & $46.74 \mathrm{kl}$ & 12.84 & 47 & $3.95 \mathrm{~d}-\mathrm{h}$ & $2.93 \mathrm{j}-\mathrm{o}$ & k-p & & d-h & $7.281-1$ & & \\
\hline tih & 6 & 24.6 & & $34.88 \mathrm{ab}$ & & 47.0 & & & & & & & & & & \\
\hline & & & & & & & & & & & & & & & & \\
\hline & $.07 \mathrm{ab}$ & $35.80 \mathrm{f}-\mathrm{j}$ & $21.441-\mathrm{r}$ & $39.11 \mathrm{a}$ & $119.78 \mathrm{a}$ & $60.03 \mathrm{ij}$ & $20.11 \mathrm{p}$ & $00.05 \mathrm{a}$ & $5.25 \mathrm{~b}$ & $d-1$ & $2.88 \mathrm{j}-\mathrm{o}$ & & $11.49 \mathrm{a}$ & 7.03 & & \\
\hline & $.25 \mathrm{~h}-\mathrm{k} 1$ & $13.93 \mathrm{q}-$ & $10.85 \mathrm{~s}-\mathrm{v}$ & $19.35 \mathrm{~h}$ & $66.13 \mathrm{~h}_{1}$ & 29.82 o & $10.69 \mathrm{qr}$ & $35.55 \mathrm{~h}_{1}$ & 3.32 & $2.01 \mathrm{o}-\mathrm{t}$ & tu & & g-k & & & \\
\hline . & $32.60 \mathrm{ij}$ & $17.77 \mathrm{o}-\mathrm{v}$ & $12.83 \mathrm{q}-\mathrm{v}$ & $21.06 \mathrm{gh}$ & $66.26 \mathrm{~h}_{1}$ & $36.17 \mathrm{mno}$ & $12.55 \mathrm{pqr}$ & 38.33 ghı & $3.50 \mathrm{~g}-1$ & $2.25 \mathrm{o}-\mathrm{s}$ & $1.00 \mathrm{u}$ & gh & $d-1$ & & & \\
\hline 然 & $43.50 \mathrm{c}-\mathrm{g} 1$ & $17.67 \mathrm{o}-\mathrm{v}$ & $9.57 \mathrm{uv}$ & $23.58 \mathrm{fgh}$ & 62.901 & 29.86 o & $9.57 \mathrm{r}$ & 34.111 & $3.66 \mathrm{e}-\mathrm{j}$ & 2.44 m-r & $1.58 \mathrm{q}-\mathrm{u}$ & & & & & \\
\hline 24 & 35.33 & $17.20 \mathrm{o}-\mathrm{v}$ & $9.43 \mathrm{v}$ & $20.65 \mathrm{gh}$ & 65.331 & 35.98 no & $9.79 \mathrm{r}$ & $37.03 \mathrm{gh} 1$ & $3.56 \mathrm{~g}-\mathrm{k}$ & 2.42 & $1.49 \mathrm{r}-\mathrm{u}$ & $2.49 \mathrm{fgh}$ & $7.36 \mathrm{~h}-1$ & 5.59 & $1.49 \mathrm{tu}$ & $1 \mathrm{de}$ \\
\hline L 5 & $48.00 \mathrm{~cd}$ & $29.461-1$ & $\mathrm{n}-\mathrm{u}$ & $32.08 \mathrm{bc}$ & 88.96 ef & $53.60 \mathrm{jk}$ & $15.08 \mathrm{p}$ & 52 & $b-f$ & $3.63 \mathrm{f}-\mathrm{j}$ & 3.25 h-n & $2 \mathrm{ab}$ & c-f & $7.73 \mathrm{f}-\mathrm{k}$ & & $a b c$ \\
\hline L 582 & $38.05 \mathrm{e}-12$ & $28.63 \mathrm{j}-\mathrm{m}$ & $12.52 \mathrm{r}-\mathrm{v}$ & $26.40 \mathrm{def}$ & $84.42 \mathrm{f}$ & $45.87 \mathrm{kl}$ & $18.65 \mathrm{pq}$ & $49.65 \mathrm{c}-\mathrm{f}$ & $4.61 \mathrm{~b}-\mathrm{e}$ & $2.87 \mathrm{j}-\mathrm{o}$ & $1.54 \mathrm{q}-\mathrm{u}$ & $3.01 \mathrm{c}-\mathrm{f}$ & $9.37 \mathrm{bcd}$ & $7.04 \mathrm{j}-\mathrm{m}$ & $3.15 \mathrm{q}$ & $6.52 \mathrm{abc}$ \\
\hline & 46.33 cde 2 & $25.22 \mathrm{k}-\mathrm{o}$ & $12.21 \mathrm{r}-\mathrm{v}$ & $27.92 \mathrm{c}-\mathrm{f}$ & $74.27 \mathrm{gh}$ & 60.68 no & $12.47 \mathrm{pqr}$ & $39.14 \mathrm{gh}$ & $4.07 \mathrm{c}-\mathrm{h}$ & $2.961-0$ & & & & & & \\
\hline & $1 \mathrm{a}$ & & $12.62 \mathrm{c}$ & & $5.25 \mathrm{a}$ & $41.21 \mathrm{~b}$ & $12.84 \mathrm{c}$ & 46.77 & $4.31 \mathrm{a}$ & & & 3.22 & & & & (5) \\
\hline & & & & GxT:8.78 & G:4.71 & & & GxT:8.15 & G:0.52 & & & & G:0.74 & & Т:0.32 & \\
\hline & $\mathrm{G}: * *$ & & $\mathrm{~T}: * *$ & GxT:** & 3. & & $\mathrm{T}: * *$ & UX1. & U. & & $\mathrm{T}: * *$ & SNA. & & & & GxT:** \\
\hline
\end{tabular}


Çizelge 3. Tuz dayanıklılık ve Tohum güç indeksi özelliklerine ilişkin ortalama değerler.

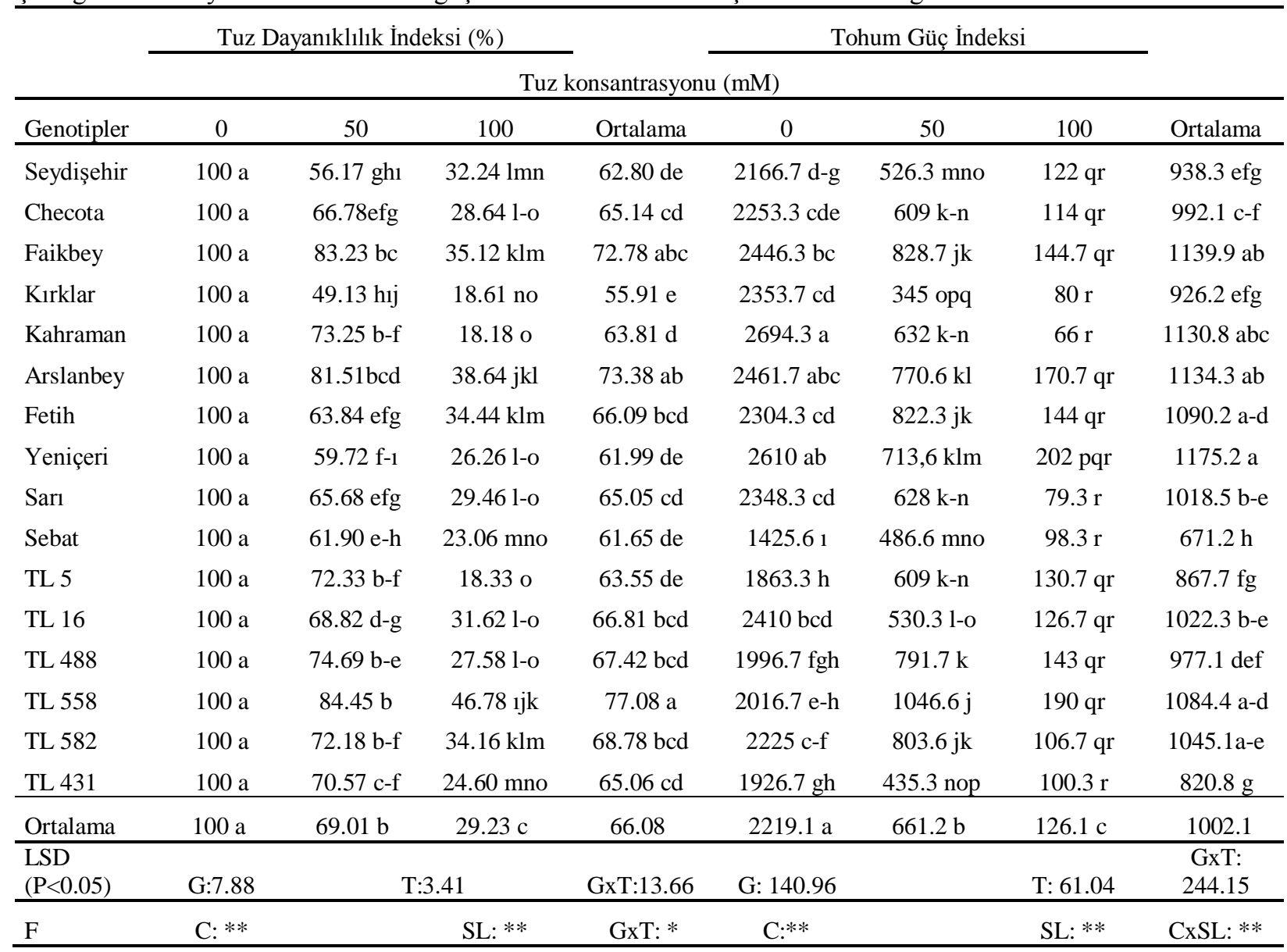

Genotipler arasında en yüksek kök kuru ağırlığı Sarı (4.02 mg) genotipinden, en yüksek sürgün kuru ağırlığ 1 ise Kahraman $(7.05 \mathrm{mg})$ genotipinden elde edilmiştir. Artan tuz konsantrasyonları kök ve sürügün kuru ağırlıkları üzerindeki etkileri olumsuz yönde olmuş ve tuz konsantrasyonu arttıkça kuru ağırlıklarda da azalmalar meydana gelmiştir. Tuz konsantrasyonlarındaki artış sürgün gelişimini kök gelişimine oranla daha fazla etkilemiştir (Çizelge 2). Çalışmamız, bu durumla ilgili olarak Doğan ve Budaklı Çarpıcı (2016)'nın çalışmasıyla uyum içerisindedir. GenotipxTuz konsantrasyonu interaksiyonu önemli çıkmıştır. Kök kuru ağıllıkları 1.00 mg (TL 5-100mM) $6.31 \mathrm{mg}$ (Kırklar-0 $\mathrm{mM}$ ), sürgün kuru ağırlıkları ise 1.10 $\mathrm{mg}$ (TL 5-100 mM)-11.49 mg (Sar1-0 mM) arasinda değişmiştir (Çizelge 2).

Yulaf genotipleri arasında tohum güç indeksi bakımından önemli farklılıklar ortaya çıkmıştır. En yüksek tohum güç indeksi Yeniçeri, en düşük tohum güç indeksi ise Sebat genotipinden tespit edilmiştir. Artan tuz konsantrasyonları sonucunda tohum güç indeksi değerleri önemli ölçüde azalmış ve kontrol doza göre 100 $\mathrm{mM}$ tuz dozunda tohum güç indeksi değerinde $\% 94$ azalma meydana gelmiştir (Çizelge 3). Tohum güç indeksi bakımından Genotip x Tuz konsantrasyonu interaksiyonu önemli çıkmış ve bunun sonucunda da Kahraman çeşidi 2694.3 ile $0 \mathrm{mM}$ tuz dozunda en yüksek tohum güç indeksi değerine sahip olurken, yine
Kahraman çeşidi 66 ile $100 \mathrm{mM}$ tuz dozunda en düşük değere sahip olmuştur (Çizelge 3). Benzer sonuç, Atak (2014) tarafindan da tespit edilmiştir.

Yulaf genotipleri arasında erken fide dönemi için tuz dayanıklılık indeksi bakımından önemli farklılıklar ortaya çıkmıştır. Tuz dayanıklılık indeksi, $50 \mathrm{mM}$ için \% 49.13 - 84.45 arasında değişirken $100 \mathrm{mM}$ için ise \% 18.61 - 46.78 arasında değişmiştir. Ortalama sonuçlara göre ise \%55.91 - 77.08 arasında değişmiştir. TL 558, Arslanbey ve Faikbey genotipleri tuz dayanıklılık indeksi için en iyi performansı gösteren genotipler olmuştur (Çizelge 3). Benzer şekilde, Çarpıcı ve ark. (2009) ve Kökten ve ark. (2010) artan tuz konsantrasyonuna bağl1 olarak tuz stress toleransının azaldığını bildirmişlerdir.

\section{SONUÇ}

Araştırma sonuçları hem çimlenme özelliklerinin hem de fide gelişiminin ortamdaki tuz yoğunluğundan önemli derecede etkilendiğini göstermiş̧ir. Çimlenme yüzdelerinin $50 \mathrm{mM} \mathrm{NaCl}$ konsatrasyonunda \%80'in üzerinde, $100 \mathrm{mM} \mathrm{NaCl}$ konsatrasyonunda ise $\% 45^{\prime}$ 'lere düşmesi yulaf tohumlarının orta tuz dozlarında çimlenebileceğini göstermiştir. Tuz dayanıklılık indeksi değerleri bakımından daha iyi performans gösteren TL 558, Arslanbey ve Faikbey genotiplerinin tuz konsantrasyonu yüksek olan alanlar için çimlenme ve ilk fide döneminde diğer genotiplerden daha avantajlı olduğu ortaya çıkmaktadır. 


\section{TEŞEKKÜR}

Bu çalışma Düzce Üniversitesi Bilimsel Araştırma Projeleri Destek Programı kapsamında desteklenen 2016.11.04.454 nolu projenin bir kısmını içermektedir.

\section{KAYNAKLAR}

Akbarimoghaddam H, Galavi M, Ghanbari A, Panjehkeh N 2011. Salinity Effects on Seed Germination and Seedling Growth of Bread Wheat Cultivars. Trakia Journal of Sciences, 9(1): 43-50.

Al-Mutawa MM 2003. Effect of Salinity on Germination and Seedling Growth of Chickpea (Cicer arietinum L.) Genotypes. International Journal of Agriculture \& Biology, 5(3): 226-229.

Atak M 2014. Ekmeklik Buğday Genotiplerinin Çimlenme Aşamasında Oluşturulan Tuz Stresine Tepkilerinin Belirlenmesi. MKÜ Ziraat Fakültesi Dergisi, 19(1): 1-10.

Atak M, Kaya MD, Kaya G, Kıllı Y, Çiftçi CY 2006. Effects of $\mathrm{NaCl}$ on the Germination, Seedling Growth and Water Uptake of Triticale. Turkish Journal of Agriculture and Forestry, 30: 39-47.

Atış İ 2011. Bazı Silajlık Sorgum (Sorghum bicolor L. Moench) Çeşitlerinin Çimlenme ve Fide Gelişimi Üzerine Tuz Stresinin Etkileri. Süleyman Demirel Üniversitesi Ziraat Fakültesi Dergisi, 6(2): 58-67.

Çarpıcı E, Çelik N, Bayram G 2009. Effects of Salt Stress on Germination of Some Maize (Zea mays L.) Cultivars. African Journal of Biotechnology, 8(19): 4918-4922.

Dhanda S, Sethi GS, Behl RK 2004. Indices of Drought Tolerance in Wheat Genotypes at Early Stages of Plant Growth. Journal of Agronomy and Crop Science, 190: 6-12.

Doğan R, Budaklı Çarpıcı E 2015. Bazı Makarnalık Buğday (Triticum turgidum L.) Genotiplerinin Çimlenme Döneminde Tuz Stresine Tepkileri. U.Ü. Ziraat Fakültesi Dergisi, 29(1): 47-55.
Doğan R, Budaklı Çaprıcı E 2016. Farklı Tuz Konsantrasyonlarının Bazı Tritikale Hatlarının çimlenmesi Üzerine Etkileri. KSÜ Doğa Bilimleri Dergisi, 19(2): 130-135.

FAO 2000. Global Network on Integrated Soil Management for Sustainable Use of Salt Effected Soil. Available in: http:/www.fao.org/arg/AGL/agll/spush/intro.htm

JMP. 2007. JMP User Guide, Release 7 Copyright (C) 2007, SAS Institute Inc., Cary, NC, USA, ISBN 9781-59994-408-1.

Kara B, Akgün İ, Altındal D 2011. Tritikale Genotiplerinde Çimlenme ve Fide Gelişimi Üzerine Tuzluluğun $(\mathrm{NaCl})$ Etkisi. Selçuk Tarım ve Gıda Bilimleri Dergisi, 25(1): 1-9.

Kökten K, Karaköy T, Bakoğlu A, Akçura M 2010. Determination of Salinity tolerance of Some Lentil (Lens culinaris M.) Varieties. Journal of Food, Agriculture \& Environment, 8(1): 140-143.

Kumar A, Agarwal S, Singh A 2014. Salinity Effects The Germination and Seedling Growth in Some Cultivars of Oat (Avena sativa L.). Indian Journal of Advances in Plant Research, 1(2): 1-10.

Mahmood T, Iqbal N, Raza H, Qasım M, Ashraf MY 2010. Growth Modulation and Ion Partitioning in Salt Stressed Sorghum (Sorghum bicolor L.) by Exogenous Supply of Salicylic Acid. Pakistan Journal of Botany, 42(5): 3047-3054.

$\mathrm{Mu} \mathrm{Y,} \mathrm{Lin} \mathrm{J,} \mathrm{Mu} \mathrm{C,} \mathrm{Gao} \mathrm{Z} \mathrm{2015.} \mathrm{Effects} \mathrm{of} \mathrm{NaCl} \mathrm{Stress}$ on the Growth and Physiological Changes in Oat (Avena sativa) Seedlings. Not Bo Horti Agrobo, 43(2): 468-472.

Nawaz K, Talat A, Iqra Hussain K, Majeed A 2010. Induction of Salt Tolerance in Two Cultivars of Sorghum (Sorghum bicolor L.) by Exogenous Application of Proline at Seedling Stage. World Applied Sciences Journal, 10(1): 93-99.

Uyanık M, Kara ŞM, Korkmaz K 2014. Bazı Kışlık Kolza (Brassica napus L.) Çeşitlerinin Çimlenme Döneminde Tuz Stresine Tepkilerinin Belirlenmesi. Tarım Bilimleri Dergisi, 20: 368-375. 